\title{
Desempenho de genótipos de feijão carioca no Cerrado Central do Brasil
}

\section{Performance of carioca bean genotypes in Central Savannah's Brazil}

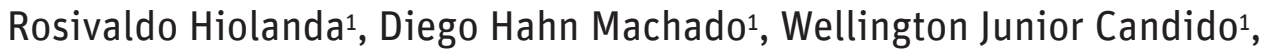 \\ Luís Cláudio de Faria² e Flávio Carlos Dalchiavon ${ }^{1, *}$ \\ ${ }^{1}$ Instituto Federal de Educação Ciência e Tecnologia de Mato Grosso - Campus Campo Novo do Parecis, curso de Bacharelado em Agronomia, MT 235, km 12, Zona Rural, \\ CEP 78360-000 Campo Novo do Parecis, MT, Brasil. \\ ${ }_{2}^{2}$ Empresa Brasileira de Pesquisa Agropecuária (Embrapa), Embrapa Arroz e Feijão, Pesquisador de Melhoramento do Feijoeiro-comum, Santo Antônio de Goiás, G0, Brasil \\ (*E-mail:flavio.dalchiavon@cnp.ifmt.edu.br) \\ http://dx.doi.org/10.19084/RCA17285
}

Recebido/received: 2017.11 .08

Recebido em versão revista/received in revised form: 2018.04.22

Aceite/accepted: 2018.04.25

\begin{abstract}
R E S U M O
O feijão comum é cultivado por pequenos, médios e grandes produtores em diferentes regiões do mundo e épocas de cultivo, sendo a época da seca ( $2^{2}$ safra) a apreciada pelos agricultores. O objetivo do estudo foi avaliar o desempenho e produtividade de feijão carioca nas condições de Cerrado de Campo Novo do Parecis, Mato Grosso (Brasil). Foi realizado em dois anos, entre os meses de fevereiro a maio de 2016 e 2017, na área experimental do Instituto Federal de Educação, Ciência e Tecnologia de Mato Grosso - IFMT. O delineamento experimental foi em blocos casualizados, com vinte tratamentos (genótipos) e três repetições. Os dados foram submetidos à análise de variância e ao teste de média Scott-Knott a 5\% de probabilidade. Para as características vegetativas altura da planta e diâmetro do caule, quando observada à adaptação à colheita mecânica (altura $>40 \mathrm{~cm}$ ) e ausência de acamamento, tanto os genótipos padrão quanto as linhagens se destacam. Em termos de precocidade, todos os genótipos são aptos ao cultivo na região Central do Brasil. Os genótipos CNFC 15805, CNFC 15820, CNFC 15743, CNFC 15801 e CNFC 15853 apresentaram potenciais produtivos superiores (acima de $460 \mathrm{~kg} \mathrm{ha}^{-1}$ ) aos demais (inclusive aos genótipos padrão), cujas produtividades ficaram abaixo de $443 \mathrm{~kg} \mathrm{ha}^{-1}$, ainda que estatisticamente iguais.
\end{abstract}

Palavras-chave: leguminosa, melhoramento genético vegetal, Phaseolus vulgaris, valor de cultivo e uso.

\begin{abstract}
A B S T R A C T
The common bean is cultivated by small, medium and large producers in different regions of the world and times of cultivation, being the time of the drought (2nd harvest) more appreciated by the farmers. The objective of this study was to evaluate the performance and productivity of carioca beans in Cerrado of Campo Novo do Parecis, Mato Grosso, Brazil. The study was conducted in two years, between February and May 2016 and 2017, in the experimental area of the Federal Institute of Education, Science and Technology of Mato Grosso - IFMT. The experimental design was in randomized blocks, with twenty treatments (genotypes) and three replications. Data were submitted to analysis of variance and the Scott-Knott mean test at 5\% probability. For the vegetative characteristics plant height and stem diameter, when observed to the adaptation to the mechanical harvest (height $>40 \mathrm{~cm}$ ) and absence of lodging, standard genotypes and the lines stand out. In terms of precocity, all genotypes are suitable for cultivation in the Central's Brazil. The genotypes CNFC 15805, CNFC 15820, CNFC 15743, CNFC 15801 and CNFC 15853 showed higher yield potentials (above $460 \mathrm{~kg} \mathrm{ha}^{-1}$ ) to the others (including the standard genotypes), whose yields were below $443 \mathrm{~kg}^{-1}$, which are statistically the same.
\end{abstract}

Keywords: leguminous, genetic plant breeding, Phaseolus vulgaris, cultivation value and use. 


\section{INTRODUÇÃO}

O feijão comum (Phaseolus vulgaris L.) é uma leguminosa de grande importância agrícola e alimentar, sendo amplamente distribuído em todo o território brasileiro, cultivado por pequenos, médios e grandes produtores (Santos et al., 2015; Dalchiavon et al., 2016), destacando-se como um produto agrícola de grande importância sócio-económica, devido principalmente à mão-de-obra utilizada durante o ciclo da cultura e o número de cultivos anual possíveis nas diversas regiões (Dalchiavon et al., 2011).

A produção varia de acordo com as condições edafoclimáticas de cada região, sendo cultivado em diferentes épocas do ano (Bertoldo et al., 2009; Dalchiavon et al., 2016). Na safra 2015/16, o estado de Mato Grosso obteve as produtividades de 1.630 (1ª época; safra das águas), 1.589 (2ª época; safra da seca) e $2.352 \mathrm{~kg} \mathrm{ha}^{-1}$ (3 ${ }^{a}$ época; safra de inverno), sendo esta última com a aplicação de irrigação (CONAB, 2015).

A sementeira da $2^{\underline{a}}$ época em Mato Grosso ocorreu entre os meses de janeiro a março, e a colheita é realizada entre março a julho, época de baixos índices pluviométricos, o que contribuiu para a qualidade do produto. Porém, o seu cultivo nem sempre trouxe resultados satisfatórios, principalmente quando as condições pluviométricas não terem ocorrido de forma homogénea durante os estádios de desenvolvimento da cultura, provocando abortamento de flores e vagens (Silva et al., 2006), o que se refletiu na queda na produtividade de grãos. Logo, torna-se necessária a adoção de sistema de irrigação para amenizar tais impactos e além disso esta tecnologia apresenta outra grande vantagem devido a redução do uso de produtos fitossanitários, pois a incidência de pragas e doenças foi menor, quando comparada com a safra das águas.

Existem diversos fatores que ocasionam perdas na produtividade do feijão, principalmente as doenças, a adaptabilidade ao ambiente, excesso e falta de água etc. Assim, todos os genótipos devem passar por testes em campos de produção em diferentes regiões, procurando-se genótipos mais adaptados e que proporcionem melhor desempenho produtivo para cada local. Desta forma os testes de Valor de Cultivo e Uso (VCU) tornam-se de suma importância paraobter informações concretas sobre cada genótipo, quanto ao seu desempenho vegetativo e reprodutivo, para que possam ser seguramente recomendados para as regiões produtoras (Carneiro, 2006).

A adaptabilidade de genótipos de feijão comum, específicos para cada região, traz uma série de benefícios ao agricultor, uma vez que nem todas as cultivares respondem bem, em todas as regiões, em virtude das condições ambientais locais, tais como a temperatura, humidade e principalmente o fotoperíodo, que interferem no desenvolvimento da cultura, reduzindo de forma significativa a sua produtividade. Assim, têm sido realizados estudos com o objetivo de auxiliar na indicação de cultivares com alta capacidade produtiva, estabilidade e adaptabilidade para diversas regiões do país (Melo et al., 2007; Pereira et al., 2009).

Todas as culturas com o passar dos anos tendem a diminuir a sua capacidade produtiva devido à presença de doenças, pragas e práticas de manipulação inadequadas, tornando-se fundamental para tal estudos de novos genótipos que, através do melhoramento genético possam substituir aqueles que já não são tão viáveis ao cultivo em larga escala.

Atualmente, estão em desenvolvimento novos genótipos com características de interesse. A região de Campo Novo do Parecis - MT tem apresentado diminuição nas áreas de cultivo de feijão, de forma que pesquisas locais para obtenção de informações técnicas referentes ao desempenho agronómico destes genótipos, dando suporte técnico aos agricultores da região na escolha da melhor opção. Para tal, foi avaliado o desempenho agronómico e a produtividade de grãos de genótipos de feijão carioca na região de Campo Novo do Parecis Mato Grosso (Brasil).

\section{MATERIAL E MÉTODOS}

O estudo foi efetuado em dois anos, entre os meses de fevereiro a maio de 2016 e 2017, na área experimental do Instituto Federal de Educação, Ciência e Tecnologia de Mato Grosso - IFMT, Campus Campo Novo dos Parecis - MT, cujas coordenadas 
geográficas são latitude S 13²0'31', longitude O 5753'31" e altitude média de $574 \mathrm{~m}$.

O clima da região, segundo a classificação de Köppen, é do tipo $\mathrm{A}_{\mathrm{w}}$ clima tropical com seca no inverno e chuva no verão. A estação seca da região é bem definida e ocorre entre os meses de maio a setembro e a chuvosa de outubro a abril (Dallacort et al., 2011).

As médias ocorridas durante o período experimental foram: 24,$1 ; 31,6$ e $19,5^{\circ} \mathrm{C}$ (2016) e de 24,0 ; 31,1 e $19,9{ }^{\circ} \mathrm{C}$ (2017) para as temperaturas média, máxima e mínima, respectivamente, assim como precipitações acumuladas de 447,6 (2016) e 603,4 mm para 2017 (Figuras 1a,b), o que atende perfeitamente à necessidade hídrica da cultura, que está entre 300 e $600 \mathrm{~mm}$ para o estado de Mato Grosso, regularmente distribuídos ao longo do seu ciclo (Santos et al., 2013).

O solo da área experimental, segundo o Sistema Brasileiro de Classificação de Solos (Embrapa, 2013) e referido em Dalchiavon et al. (2015), é Latossolo Vermelho distróférrico típico, com relevo suave ondulado e com boa drenagem.

O delineamento experimental utilizado foi em blocos casualizados (DBC), com 20 tratamentos (17 linhagens e três genótipos de feijão carioca, tidos como padrão) com três repetições, totalizando 60 parcelas. Cada repetição teve como parcela, quatro linhas espaçadas de $0,45 \mathrm{~m}$, com $5 \mathrm{~m}$ de comprimento, totalizando $9,0 \mathrm{~m}^{2}$.

A área utilizada para a sementeira do feijão estava em repouso na safra 2015/16 e com milheto na safra 2016/17 como planta de cobertura, que foi dessecado 20 dias antes da sementeira do feijão. $\mathrm{Na}$ dessecação, utilizou-se glifosato $792,5 \mathrm{~g} \mathrm{~kg}^{-1}$ (2,5 L p.c. ha- ${ }^{-1}$ ) e posteriormente, visando o controle de pragas (Spodoptera frugiperda, Rhopalosiphum maidis e Diabrotica speciosa) presentes na cultura do milheto, foram aplicados os inseticidas Metomil $215 \mathrm{~g} \mathrm{~L}^{-1}$ (1,0 L p.c. ha-1), Acefato $750 \mathrm{~g} \mathrm{~kg}^{-1}$ $\left(1,0 \mathrm{~kg}\right.$ p.c. ha- $\left.{ }^{-1}\right)$ e Teflubenzurom $150 \mathrm{~g} \mathrm{~L}^{-1}$ (200 mL p.c. ha-1), deixando a área apta à semeadura.

A demarcação das linhas de sementeira, bem como a adubação, foi realizada com auxílio de um trator e uma semeadora-adubadora. Visando a prevenção contra a larva alfinete (Diabrotica speciosa) e doença do solo (Fusarium oxysporum), foi realizado o tratamento de semente com Piraclostrobina $25 \mathrm{~g} \mathrm{~L}^{-1}$, Tiofanato Metílico $225 \mathrm{~g} \mathrm{~L}^{-1}$ e Fipronil $250 \mathrm{~g} \mathrm{~L}^{-1}$ (200 mL p.c./100 kg de sementes), procedendo-se à sementeira manual, à profundidade de $0,05 \mathrm{~m}$, com uma população de 300.000 plantas ha-1.

$\mathrm{Na}$ adubação de sementeira, realizada em 27 de fevereiro de ambos os anos, baseada na análise química do solo e nas necessidades da cultura (Souza e Lobato, 2004) foram utilizados $200 \mathrm{~kg} \mathrm{ha}^{-1}$ do formulado $\mathrm{N}-\mathrm{P}_{2} \mathrm{O}_{5}-\mathrm{K}_{2} \mathrm{O}(10-30-20)+30 \mathrm{~kg} \mathrm{ha}^{-1} \mathrm{de}$ fosfato monoamónico ou MAP (10\% de N e 46 a $50 \%$ de $\mathrm{P}_{2} \mathrm{O}_{5}$ ). Foram realizadas duas adubações de cobertura, aos 30 e aos 45 dias após emergência (DAE), com 45 e $20 \mathrm{~kg} \mathrm{ha}^{-1}$ de azoto (ureia), respectivamente.

O controle das plantas invasoras foi realizado mediante três aplicações, nomedamente aos 15, 30 e 45 DAE através da utilização dos herbicidas Fomesafem $250 \mathrm{~g} \mathrm{~L}^{-1}\left(1,0 \mathrm{~L}^{2} \mathrm{ha}^{-1}\right)$, Haloxifope-PMetílico $240 \mathrm{~g} \mathrm{~L}^{-1}\left(0,4 \mathrm{~L} \mathrm{ha}^{-1}\right)$.

Para o controlo de pragas (Bemisia tabaci, Diabrotica speciosa, Nezara viridula e Spodoptera frugiperda) foram realizadas cinco aplicações dos inseticidas, mediante o nível de dano económico: Tiametoxam $250 \mathrm{~g} \mathrm{~kg}^{-1}\left(250 \mathrm{~mL}\right.$ p.c. ha-1), Beta-Ciflutrina $50 \mathrm{~g} \mathrm{~L}^{-1}$ $\left(100 \mathrm{~mL}^{2}\right.$ p.c. ha- $\left.{ }^{-1}\right)$, Acefato $750 \mathrm{~g} \mathrm{~kg}^{-1}\left(1 \mathrm{~kg}\right.$ p.c. ha- $\left.{ }^{-1}\right)$, Lambda-Cialotrina $50 \mathrm{~g} \mathrm{~L}^{-1}(250 \mathrm{~mL}$ p.c. ha-1) e Clorpirifós $480 \mathrm{~g} \mathrm{~L}^{-1}$ (1,5 L p.c. ha-1).

O controle de doenças (Phaeoisariopsis griseola e Uromyces appendiculatus) foi realizado utilizando-se o fungicida Difeconazol $250 \mathrm{~g} \mathrm{~L}^{-1}$ (300 mL p.c. ha-1), com aplicações aos 30, 45 e 60 dias após a semeadura (DAS).

As características agronómicas avaliadas, em 10 plantas por parcela, foram: altura da planta (APL; $\mathrm{cm})$, medindo-se da base da planta até o final da guia, com auxílio de uma trena milimétrica; diâmetro do caule (DCA; mm), medido com paquímetro digital a $5 \mathrm{~cm}$ do nível do solo; dias para o florescimento inicial (DFI), contado da sementeira até $50 \%$ das plantas se apresentarem floridas; dias para a maturação fisiológica (DMF), contado da sementeira até a colheita; número de vagens por planta (NVP), contagem em campo no momento da colheita; número de grãos por vagem (NGV), 


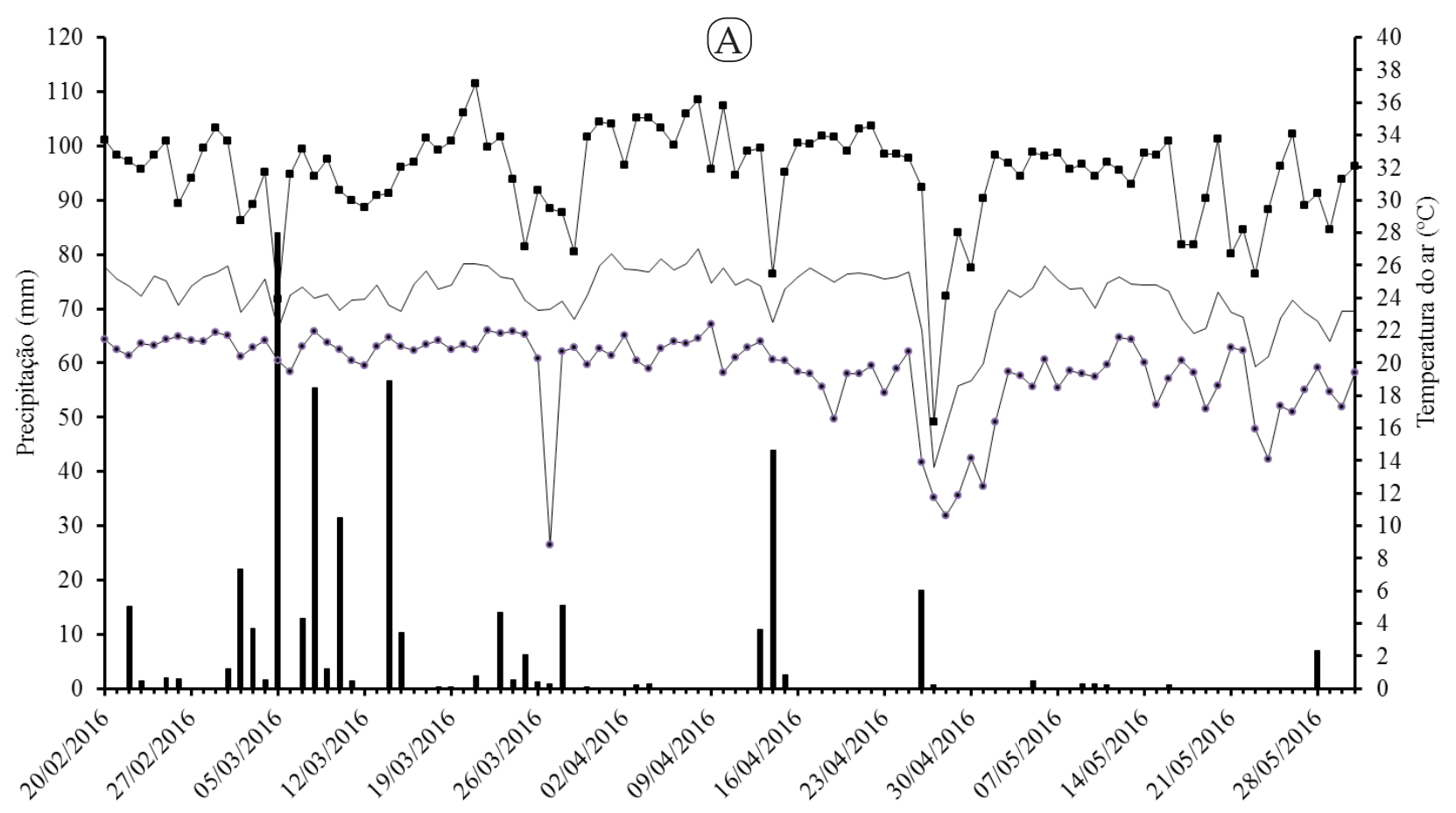

- Precipitação —Temperatura média $\rightarrow$ Temperatura máxima $\rightarrow$ Temperatura mínima

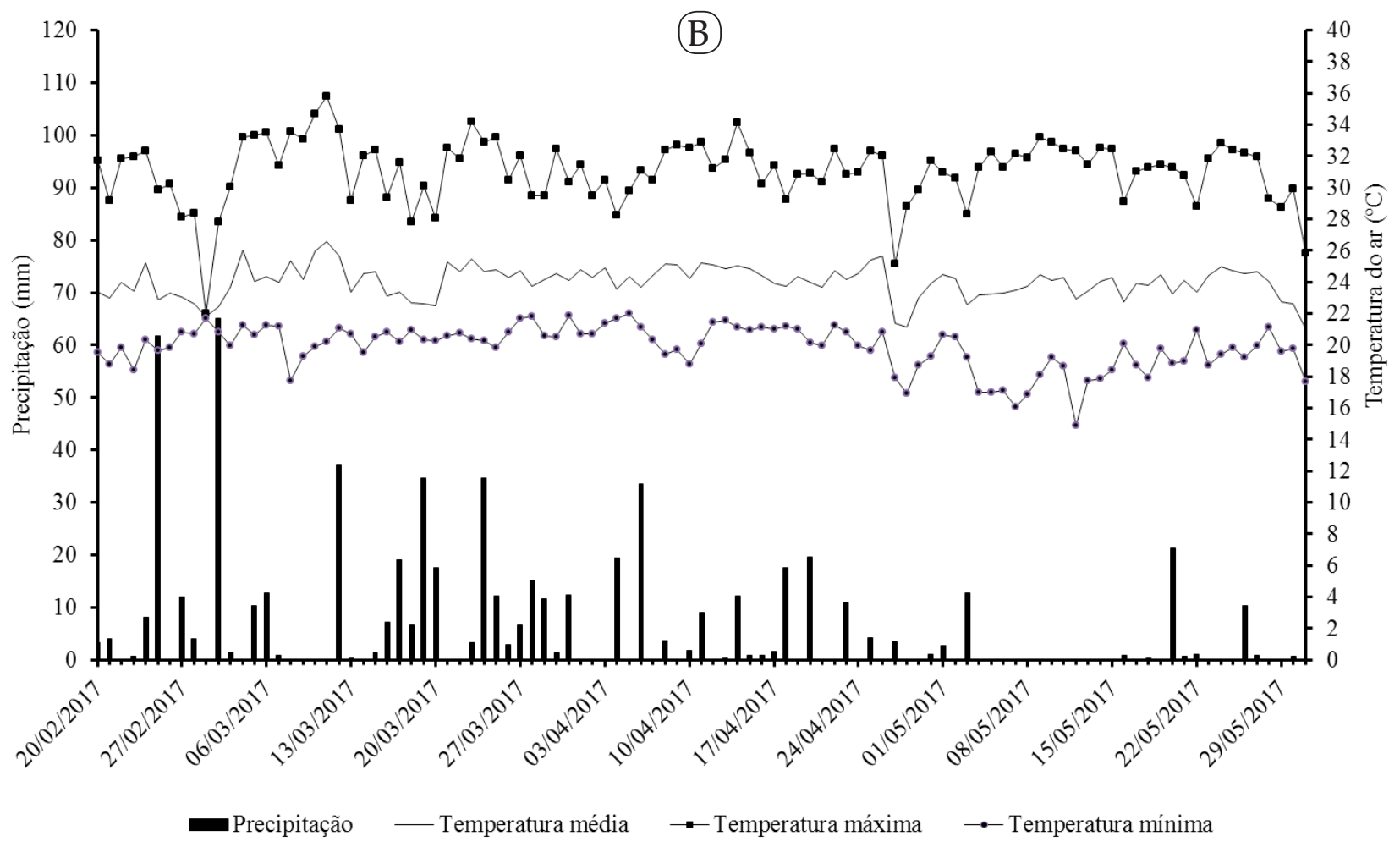

Figura 1 - Precipitação pluviométrica e médias térmicas verificadas na área experimental no período de fevereiro a maio de 2016 (a) e 2017 (b) (Campo Novo do Parecis, MT, Brasil) 
determinado por meio da contagem dos grãos e de vagens; e número de grãos por planta (NGP), obtido pelo produto entre o NVP e NGV.

Avaliou-se ainda a massa de cem grãos (MCG; g), pela contagem e pesagem $(0,01 \mathrm{~g})$ de uma amostra de 100 grãos em cada parcela da amostra e a produtividade de grãos (PRG; kg ha-1), determinada nas duas linhas centrais de 4,0 m, eliminando-se 0,5 m das extremidades. A colheita foi realizada manualmente, em 26 e 27 de maio de 2016 e 2017, respectivamente, quando as plantas atingiram $R_{9}$ (maturidade fisiológica), seguida de secagem natural e trilha mecânica (modelo Vencedora B-350), com posterior pesagem e correção da humidade dos grãos (13\% b.u.). Os dados foram submetidos à análise de variância e teste de média Scott-Knott, ambos a 5\% de probabilidade (Ferreira, 2011).

\section{RESULTADOS E DISCUSSÃO}

No Quadro 1 apresentam-se os dados referentes à análise de variância para as características agronómicas de feijão carioca da segunda safra (médias de 2016 e 2017) em Campo Novo do Parecis - MT, onde se verifica que apenas as variáveis número de grãos por vagens (NGV), número de grãos por planta (NGP), massa de cem grãos (MCG) e produtividade de grãos (PRG) não apresentaram significância estatística pelo teste $\mathrm{F}(\mathrm{p}>0,05)$.

A média geral (MG) e o coeficiente de variação (CV) para a altura da planta (APL) foram de $53,2 \mathrm{~cm}$ e $15,4 \%$ (Quadro 1), respectivamente, assim como os demais parâmetros estatísticos foram, respectivamente, de: $5,0 \mathrm{~mm}$ e $8,8 \%$ para o diâmetro do caule (DCA), 38,8 e $0,2 \%$ para o florescimento inicial (DFI), 82,5 e 0,2\% para a maturação fisiológica (DMF), 7,6 e 14,7\% para o número de vagens por planta (NVP), 3,3 e 12,4\% para o número de grãos por vagens (NGV), 24,8 e $20,4 \%$ para o número de grãos por planta (NGP), 23,5 g e 6,3\% para a massa de cem grãos (MCG) e 404,5 kg ha-1 e $13,8 \%$ para a produtividade de grãos (PRG). Tais CVs ficaram entre baixo (até $10 \%$ ) e médio (entre 10 e 20\%), segundo a magnitude definida por Pimentel-Gomes e Garcia (2002). A variação deste parâmetro estatístico ocorre em função das condições ambientais e das características agronómicas específicas avaliadas para cada genótipo.
Quadro 1-Resumo da análise de variância para as características agronómicas de feijão carioca na segunda safra (médias de 2016 e 2017), Campo Novo do Parecis, MT, Brasil

\begin{tabular}{cccc}
\hline Variáveis $^{1}$ & $\mathbf{F}^{\mathbf{2}}$ & $\mathbf{C V}(\mathbf{\%})^{3}$ & $\mathbf{M G}^{\mathbf{4}}$ \\
\hline APL $(\mathrm{cm})$ & $2,1^{*}$ & 15,4 & 53,2 \\
DCA (mm) & $1,9^{*}$ & 8,8 & 5,0 \\
DFI & $437,9^{* *}$ & 0,2 & 38,8 \\
DMF & $26,1^{* *}$ & 0,2 & 82,5 \\
NVP & $2,4^{*}$ & 14,7 & 7,6 \\
NGV & 1,6 & 12,4 & 3,3 \\
NGP & 1,7 & 20,0 & 24,8 \\
MCG (g) & 1,4 & 6,3 & 23,5 \\
PRG (kg ha $\left.{ }^{-1}\right)$ & 1,3 & 13,8 & 404,5 \\
\hline
\end{tabular}

${ }^{1} \mathrm{APL}=$ altura da planta, $\mathrm{DCA}$ = diâmetro do caule, $\mathrm{DFI}$ = dias para o florescimento inicial, $\mathrm{DMF}=$ dias para a maturação fisiológica, NVP = número de vagens por planta, NGV = número de grãos por vagens, NGP = número de grãos por planta, $M C G=$ massa de cem grãos, $P R G=$ produtividade de grãos; ${ }^{2} * \star \mathrm{e}$ * significativo a 1 e $5 \%$, respectivamente; ${ }^{3} \mathrm{CV}=$ Coeficiente de variação; ${ }^{4} \mathrm{MG}=$ Média Geral.

Os genótipos com os maiores valores (entre 52,2 e 64,9 cm) para a APL foram CNFC 15805, Pérola, CNFC 16876, CNFC 15820, CNFC 16902, CNFC 16709, CNFC 15859, CNFC 15854, ANFC9, BRS Estilo, CNFC 15743, CNFC 15801 e BRS FC402, diferindo estatisticamente dos demais genótipos (Quadro 2).

Plantas com comprimento da guia muito elevado podem interferir nas práticas de manipulação, pois estas têm o hábito de enrolar-se nas plantas ao seu redor, fazendo com que ocorra o fechamento dos corredores mais rapidamente, ao mesmo tempo em que essa é uma característica desejável ao controle de plantas invasoras, pois reduz a incidência de luz e minimiza o número de aplicações de herbicidas. Porém, devido às guias serem produtivas, ocorre maior amassamento de vagens, o que não é desejável para o agricultor.

Neste sentido, genótipos que apresentam APL média entre 40,0 e $55,0 \mathrm{~cm}$ são ideais para a colheita mecânica e tratos culturais, desde que não acamem. Assim, percebe-se que $55 \%$ dos genótipos testados são ideais à colheita mecânica. Entre os genótipos, o BRS Estilo e Pérola apresentaram a maior APL (55,6 e 54,5 cm), semelhante à de Morais et al. (2001), que avaliaram cultivares de feijão sob diferentes espaçamentos em $2^{\underline{a}}$ safra em Goiânia - GO (Brasil) e relataram para o Pérola valor de $49,2 \mathrm{~cm}$, assim como aos 51,2 cm (Pérola) observado 
Quadro 2 - Valores médios das características agronómicas em 10 plantas por parcela

\begin{tabular}{|c|c|c|c|c|c|c|c|c|c|}
\hline Genótipos & $\begin{array}{l}\text { APL } \\
(\mathrm{cm}) \\
\end{array}$ & $\begin{array}{l}\text { DCA } \\
(\mathrm{mm}) \\
\end{array}$ & DFI & DMF & NVP & NGV & NGP & $\begin{array}{c}\text { MCG } \\
\text { (g) }\end{array}$ & $\begin{array}{c}\text { PRG } \\
\left(\mathrm{kg} \mathrm{ha}^{-1}\right)\end{array}$ \\
\hline CNFC 15805 & $55,5 \mathrm{a}$ & $4,6 \mathrm{~b}$ & $38,0 \mathrm{f}$ & $82,0 \mathrm{c}$ & $6,2 \mathrm{~b}$ & $2,6 \mathrm{a}$ & $17,0 \mathrm{a}$ & $23,6 \mathrm{a}$ & $588,5 \mathrm{a}$ \\
\hline PÉROLA* & $54,5 \mathrm{a}$ & $4,6 \mathrm{~b}$ & $38,0 \mathrm{f}$ & $82,0 \mathrm{c}$ & $5,8 \mathrm{~b}$ & $3,1 \mathrm{a}$ & $20,2 \mathrm{a}$ & $23,7 \mathrm{a}$ & 423,2 a \\
\hline IPR BEM-TE-VI* & $44,9 \mathrm{~b}$ & $5,5 \mathrm{a}$ & $38,5 \mathrm{e}$ & $82,5 \mathrm{~b}$ & $8,6 \mathrm{a}$ & $3,8 \mathrm{a}$ & $30,5 \mathrm{a}$ & $21,8 \mathrm{a}$ & $348,3 \mathrm{a}$ \\
\hline CNFC 16876 & 59,0 a & $4,7 \mathrm{~b}$ & $38,0 \mathrm{f}$ & $82,0 \mathrm{c}$ & $7,7 \mathrm{a}$ & $3,2 \mathrm{a}$ & 23,0 a & $22,1 \mathrm{a}$ & $354,4 \mathrm{a}$ \\
\hline CNFC 15820 & $64,9 \mathrm{a}$ & $4,8 \mathrm{~b}$ & $40,0 \mathrm{a}$ & $82,0 \mathrm{c}$ & $7,8 \mathrm{a}$ & $3,2 \mathrm{a}$ & $24,2 \mathrm{a}$ & $24,1 \mathrm{a}$ & $483,2 \mathrm{a}$ \\
\hline CNFC 16902 & $52,2 \mathrm{a}$ & $5,0 \mathrm{~b}$ & $38,0 \mathrm{f}$ & $82,5 \mathrm{~b}$ & $9,0 \mathrm{a}$ & $3,2 \mathrm{a}$ & $28,5 \mathrm{a}$ & $22,4 \mathrm{a}$ & 337,6 a \\
\hline CNFC 15860 & $42,9 \mathrm{~b}$ & $4,8 \mathrm{~b}$ & $38,5 \mathrm{e}$ & $82,5 \mathrm{~b}$ & $7,1 \mathrm{~b}$ & $3,2 \mathrm{a}$ & $23,2 \mathrm{a}$ & $22,9 \mathrm{a}$ & $431,0 \mathrm{a}$ \\
\hline CNFC 16709 & $58,1 \mathrm{a}$ & $4,6 \mathrm{~b}$ & $38,5 \mathrm{e}$ & $82,5 \mathrm{~b}$ & $8,4 \mathrm{a}$ & $3,1 \mathrm{a}$ & $26,0 \mathrm{a}$ & $21,7 \mathrm{a}$ & $410,2 \mathrm{a}$ \\
\hline CNFC 15859 & 56,8 a & $5,0 \mathrm{~b}$ & $40,0 \mathrm{a}$ & $82,5 \mathrm{~b}$ & $7,3 \mathrm{~b}$ & $3,3 \mathrm{a}$ & $22,8 \mathrm{a}$ & $23,6 \mathrm{a}$ & $443,3 \mathrm{a}$ \\
\hline CNFC 15854 & $53,7 \mathrm{a}$ & $5,5 \mathrm{a}$ & $39,5 \mathrm{~b}$ & $82,0 \mathrm{c}$ & $10,0 \mathrm{a}$ & $3,3 \mathrm{a}$ & $32,1 \mathrm{a}$ & $23,0 \mathrm{a}$ & 353,4 a \\
\hline ANFC9 & $61,1 \mathrm{a}$ & $4,5 \mathrm{~b}$ & $38,5 \mathrm{e}$ & $83,0 \mathrm{a}$ & $6,7 \mathrm{~b}$ & $3,7 \mathrm{a}$ & $24,4 \mathrm{a}$ & $24,9 \mathrm{a}$ & $338,8 \mathrm{a}$ \\
\hline CNFC 15826 & $48,4 \mathrm{~b}$ & $4,8 \mathrm{~b}$ & $38 \mathrm{f}$ & $82,3 \mathrm{~b}$ & 7,7 a & $3,5 \mathrm{a}$ & $27,4 \mathrm{a}$ & $24,1 \mathrm{a}$ & 359,6 a \\
\hline CNFC 15839 & $44,9 \mathrm{~b}$ & $5,2 \mathrm{a}$ & $38,5 \mathrm{e}$ & $83,0 \mathrm{a}$ & 8,1 a & $3,3 \mathrm{a}$ & $25,9 \mathrm{a}$ & $25,1 \mathrm{a}$ & $348,3 \mathrm{a}$ \\
\hline BRS ESTILO* & $55,6 \mathrm{a}$ & $5,4 \mathrm{a}$ & $40,0 \mathrm{a}$ & $83,0 \mathrm{a}$ & $6,2 \mathrm{~b}$ & $3,5 \mathrm{a}$ & $21,6 \mathrm{a}$ & $24,2 \mathrm{a}$ & 385,7 a \\
\hline CNFC 15743 & $54,9 \mathrm{a}$ & $5,3 \mathrm{a}$ & $40,0 \mathrm{a}$ & $82,5 \mathrm{~b}$ & 7,7 a & $3,6 \mathrm{a}$ & $26,9 \mathrm{a}$ & $24,8 \mathrm{a}$ & $461,4 \mathrm{a}$ \\
\hline CNFC 15801 & $57,8 \mathrm{a}$ & $4,7 \mathrm{~b}$ & $39,5 \mathrm{~b}$ & $83,0 \mathrm{a}$ & $8,2 \mathrm{a}$ & $3,1 \mathrm{a}$ & $26,3 \mathrm{a}$ & $23,6 \mathrm{a}$ & $466,3 \mathrm{a}$ \\
\hline CNFC 15713 & $43,7 b$ & $5,7 \mathrm{a}$ & $39,5 \mathrm{~b}$ & $83,0 \mathrm{a}$ & $7,5 \mathrm{a}$ & $4,0 \mathrm{a}$ & $29,4 \mathrm{a}$ & $23,8 \mathrm{a}$ & 330,7 a \\
\hline CNFC 15850 & $44,6 \mathrm{~b}$ & $5,0 \mathrm{~b}$ & $38,0 \mathrm{f}$ & $82,0 \mathrm{c}$ & $7,3 \mathrm{~b}$ & $3,1 \mathrm{a}$ & $22,1 \mathrm{a}$ & $23,8 \mathrm{a}$ & $374,1 \mathrm{a}$ \\
\hline CNFC 15853 & $45,9 \mathrm{~b}$ & $5,0 \mathrm{~b}$ & $38,7 \mathrm{~d}$ & $82,5 \mathrm{~b}$ & 7,7 a & $3,3 \mathrm{a}$ & $24,5 \mathrm{a}$ & $24,0 \mathrm{a}$ & $478,1 \mathrm{a}$ \\
\hline BRS FC402 & $64,3 \mathrm{a}$ & $5,1 \mathrm{~b}$ & $39,0 \mathrm{c}$ & $82,5 \mathrm{~b}$ & $6,6 \mathrm{~b}$ & $3,1 \mathrm{a}$ & $19,2 \mathrm{a}$ & $22,4 \mathrm{a}$ & $373,3 \mathrm{a}$ \\
\hline
\end{tabular}

* = Genótipo padrão; Letras distintas diferem entre si pelo teste de Scott-Knott a $5 \%$ de probabilidade.

Altura da planta (APL), diâmetro do caule (DCA), dias para o florescimento inicial (DFI), dias para a maturação fisiológica (DMF), número de vagens por planta (NVP), número de grãos por vagens (NGV), número de grãos por planta (NGP), massa de cem grãos (MCG) e produtividade de grãos (PRG) de diferentes genótipos de feijão carioca cultivado em segunda safra (médias de 2016 e 2017), Campo Novo do Parecis, MT, Brasil

no estudo de Santos et al. (2013), no município de Alta Floresta - MT, para o cultivo no período das águas. Por outro lado, Valério et al. (1999), avaliaram o comportamento da cultivar Pérola, sob diferentes populações e espaçamentos de plantas em Lavras MG (2aa safra), e obtiveram APL de $37,0 \mathrm{~cm}$.

Para o DCA, os genótipos CNFC 15713, IPR Bem-te-vi, BRS Estilo, CNFC 15743, CNFC 15839 e CNFC 15854 apresentaram os maiores resultados (entre 5,2 e 5,7 $\mathrm{mm}$ ), diferindo dos demais genótipos cujos valores ficaram entre 4,5 e 5,1 mm (Quadro 2). O Pérola apresentou média de 4,6 mm, semelhante à obtida por Bertoldo et al. (2015), que foi de $4,5 \mathrm{~mm}$, mas superior à média $(3,4 \mathrm{~mm})$ de Vale et al. (2012), o que denota a necessidade de testes dos materiais em diferentes condições edafoclimáticas, tendo em vista a interação genótipo $\mathrm{x}$ ambiente.

O DCA é de grande importância para a arquitetura da planta, de forma que caules mais espessos e rígidos proporcionam maior sustentação e resistência à planta ao acamamento e menos vagens estarão em contato com o solo, consequentemente, ocorrerão menos doenças via solo-planta, maior qualidade do produto e menor perda na colheita (Vale et al., 2012).

Os genótipos que levaram mais dias (40) para o florescimento inicial (DFI) foram o BRS Estilo, CNFC 15743, CNFC 15859 e CNFC 15820 (Quadro 2), em contrapartida, o Pérola, CNFC 15805, CNFC 16876, CNFC 16902, CNFC 15826 e CNFC 15850 necessitaram menos dias (38) para florescerem. Por outro lado, para a maturação fisiológica (DMF), verificou-se que os genótipos mais tardios foram o CNFC 15713, CNFC 15801, BRS Estilo, CNFC 15839 e ANFC9, com total de 83,0 dias, enquanto que os mais precoces foram CNFC 15850, CNFC 15854, CNFC 15820, CNFC 16876, Pérola e CNFC 15805, com 82,0 dias. Apesar da pouca diferença entre os materiais, foi detectada diferença estatística pelo teste Scott-Knott $(p<0,05)$.

Os genótipos IPR Bem-te-vi, CNFC 16876, CNFC 15820, CNFC 16902, CNFC 16709, CNFC 15854, CNFC 15826, CNFC 15839, CNFC 15743, CNFC 
15801, CNFC 15713 e CNFC 15853 apresentaram o maior NVP, valores entre 7,5 e 10,0 (Quadro 2). Estes valores diferiram da variação observada (entre 5,8 e 7,3) para os genótipos Pérola, CNFC 15805, CNFC 15860, CNFC 15859, ANFC9, BRS Estilo, CNFC 15850 e BRS FC402. Através de pesquisas realizadas por Correa et al. (2012) em Aquidauana - MS (Brasil), ao avaliarem 13 genótipos de feijão comum de $2^{2}$ época, observaram que o Pérola apresentou NVP de 26,6, valor superior ao obtido pelo mesmo genótipo na presente pesquisa $(5,8)$.

Os genótipos (Quadros 1 e 2) não apresentaram diferença estatística para NGV, em contrapartida o Pérola obteve valor 3,1, valor inferior ao mencionado por Correa et al. (2012), que foi de 5,2. Contudo, foi semelhante ao observado por Oliveira et al. (2015) quando avaliaram feijoeiro de inverno irrigado em Cassilândia - MS (Brasil) e relataram valor de 3,2. Mesmo com a utilização de irrigação, o valor obtido pelos mencionados autores não foi satisfatório, sendo o baixo rendimento atribuído a cultivares pouco produtivas, incidência de pragas e doenças.

A variável NGP não apresentou significância estatística para os genótipos (Quadros 1 e 2). Contudo, o Pérola (padrão) apresentou valor de 20,2 para a característica em questão, diferindo do obtido por Oliveira et al. (2015), que foi de 34,7 e de Bertoldo et al. (2015), com 32,7. O baixo NGP pode ter sido ocasionado pelo estresse hídrico, o que proporciona menor viabilidade das flores e ocorrência de abortamento de vagens durante o ciclo da cultura (Oliveira et al., 2005; Guimarães et al., 2006; Ramalho et al., 2009).

Para a MCG, que não houve diferença estatística entre os genótipos testados (Quadros 1 e 2), seus valores oscilaram entre 21,7 (CNFC 16709) e 24,9 g (ANFC9). De qualquer forma, foram inferiores aos mencionados (para o Pérola) por Correa et al. (2012), com 30,1 g, e por Oliveira et al. (2015), com 30,3 g. Contudo, o baixo valor obtido neste estudo deve-se ao stresse hídrico ocorrido na fase reprodutiva (R5 e R8), momento em que a planta não tolera tal condição, assim como a temperaturas elevadas, que permaneceu acima de $30^{\circ} \mathrm{C}$ neste período (Figuras 1a, b), haja vista que Dickson et al. (1989) afirmaram que os maiores prejuízos ocorreram no subperíodo relacionado à reprodução das plantas, uma vez que temperaturas variando entre 30 e $40{ }^{\circ} \mathrm{C}$ acarretam abortamento de flores e botões florais, reduzindo o rendimento das lavouras.

Em relação à PRG também não houve diferença estatística entre os genótipos (Quadros 1 e 2), porém os valores ficaram entre 330,7 (CNFC 15713) e $588,5 \mathrm{~kg} \mathrm{ha}^{-1}$ (CNFC 15805), sendo valores considerados baixos, como se percebe nos trabalhos de Correa et al. (2012), que descreveram PRG de 2084,2 kg ha-1, e de Santos et al. (2013), para o cultivo das águas (ou seja, com total suprimento hídrico), com PRG de 1621,0 kg ha-1, ambos para o Pérola, assim como inferior à média nacional de feijão $2^{\text {a }}$ safra (2015/16), que foi de 964,0 kg ha $^{-1}$ (CONAB, 2015). Contudo, além das condições climáticas desfavoráveis, a baixa produtividade ocorreu em função das altas infestações de pragas (Bemisia tabaci e Diabrotica speciosa), o que acarretou em morte de plantas, abortamento de flores e vagens. De acordo com Aguiar et al. (2008), o stresse hídrico é a segunda causa para redução da produtividade de grãos, superada apenas pela ocorrência de doenças.

No que se refere à distribuição irregular das chuvas, entre os meses de abril e maio de 2016 e 2017 (Figura 1a, b), estas afetaram o enchimento dos grãos, que ficaram, em grande parte, engelhados devido ao stresse hídrico, que reduziu a fotossíntese, tornando escassa a disponibilidade de fotossintatos para o enchimento das vagens, acarretando a queda das mesmas, o que também foi verificado por O'Toole et al. (1977).

Salienta-se ainda que as necessidades hídricas para o bom desenvolvimento da cultura é de $100 \mathrm{~mm}$ mensal, distribuídas de forma homogénea no decorrer do seu desenvolvimento, aliada a temperaturas médias $\left(18\right.$ a $30^{\circ} \mathrm{C}$ ), uma vez que a cultura apresenta sistema radicular pouco desenvolvido, sendo sensível ao stresse hídrico e quando passa por determinadas situações, em função do estádio fenológico em que a mesma se encontra, a sua capacidade de recuperação torna-se muito lenta, acarretando a rendimentos produtivos muito baixos (Back, 2001), facto que foi observado no presente estudo, uma vez que a precipitação foi muito desuniforme (Figuras 1a,b), não atendendo às necessidades da cultura em R5 (início do florescimento) e R8 (fase de enchimento de grãos), fases em que 
a necessidade hídrica é maior, e quando não atendida, provoca o abortamento de flores e vagens, refletindo-se no baixo desempenho produtivo das plantas.

Adicionalmente, de acordo com Back (2001), trabalhos demonstram que os défices hídricos por períodos de 14, 17 e 20 dias, durante as fases da emergência e da floração, reduzem a produtividade de grãos em 20, 38 e 52\%, respectivamente. Dado o exposto, verifica-se que as condições edafoclimáticas nas quais o feijão é cultivado refletem-se diretamente no desempenho reprodutivo do mesmo, de forma que a seca é o fator que mais contribui para o seu insucesso (Guimarães et al., 2006; Ramalho et al., 2009), levando a uma baixa produtividade de grãos (Oliveira et al., 2005), como foi observado no presente estudo, sobretudo em 2016, quando abril foi praticamente seco, exceto no dia 14, em que precipitaram $44 \mathrm{~mm}$, após 15 dias sem chuvas em pleno período reprodutivo da cultura, o que refletiu no baixo desempenho produtivo, tanto do mencionado ano como na composição das médias dos dois anos. Da mesma forma, o mês de maio foi bem seco, em ambos os anos (Figuras 1a,b), momento final do enchimento de grãos.

\section{CONCLUSÕES}

Para as características vegetativas altura da planta e diâmetro do caule, quando observada à adaptação à colheita mecânica (altura $>40 \mathrm{~cm}$ ) e ausência de acamamento, tanto os genótipos padrão quanto as linhagens se destacam.

Em termos de precocidade, todos os genótipos são aptos ao cultivo no Cerrado Central do Brasil.

Os genótipos CNFC 15805, CNFC 15820, CNFC 15743, CNFC 15801 e CNFC 15853 apresentaram potenciais produtivos superiores (acima de $460 \mathrm{~kg}$ ha $^{-1}$ ) aos demais (inclusive aos genótipos padrão), cujas produtividades ficaram abaixo de $443 \mathrm{~kg} \mathrm{ha}^{-1}$, ainda que estatisticamente iguais.

\section{AGRADECIMENTOS}

Ao Grupo de Pesquisa em Fitotecnia (GPF), do Instituto Federal de Educação Ciência e Tecnologia de Mato Grosso - Campus Campo Novo do Parecis, pelo suporte e auxílio na condução do trabalho e à Empresa Brasileira de Pesquisa Agropecuária (Embrapa Arroz e Feijão - CNPAF), pelo apoio ao estudo.

\section{REFERÊNCIAS BIBLIOGRÁFICAS}

Aguiar, R.S.; Cirino, V.M.; Faria, R.T. e Vidal, L.H.I. (2008) - Avaliação de linhagens promissoras de feijoeiro (Phaseolus vulgaris L.) tolerantes ao déficit hídrico. Ciências Agrárias, vol. 29, n. 1, p. 1-14. http://dx.doi. org/10.5433/1679-0359

Back, A.J. (2001) - Necessidade de irrigação da cultura de feijão no sul do estado de Santa Catarina. Revista de Tecnologia e Ambiente, vol. 7, n. 1, p. 35-44.

Bertoldo, G.J.; Coimbra, M.M.L.J.; Gilcimar Vogt, A.; Hemp, S.; Rocha, da F.; Stahelin, D. e Tavares, E. H. (2009) - Adaptabilidade e estabilidade fenotípica para o caráter tempo de cocção do feijão preto. Revista Ceres, vol. 56, n. 3, p. 315-321.

Bertoldo, G.J.; Pelisser, A.; Silva da P.R.; Favreto, R. e Oliveira de D.A.L. (2015) - Alternativas na fertilização de feijão visando a reduzir a aplicação de N-ureia. Pesquisa Agropecuária Tropical, vol. 45, n. 3, p. 348-355. http://dx.doi.org/10.1590/1983-40632015v4534885

Carneiro, G.E de S. (2006) - Desenvolvimento de Novas Cultivares para o Agronegócio do Feijão. Embrapa Soja. Documentos, 308.

CONAB (2015) - Feijão. Acompanhamento de safra. Conjuntura Mensal, janeiro de 2015. 154 p. Brasília. Companhia Nacional de Abastecimento [cit. 2016.08.24]. http://www.conab.gov.br

Correa, M.A. e Gonçálves, C.M. (2012) - Divergência genética em genótipos de feijão comum cultivados em Mato Grosso do Sul. Revista Ceres, vol. 59, n. 2, p. 206-212. http://dx.doi.org/10.1590/S0034-737X2012000200009 
Dalchiavon, F.C.; Carvalho, M.P.; Freddi, O.S.; Andreotti, M. e Montanari, R. (2011) - Variabilidade espacial da produtividade do feijoeiro correlacionada com atributos químicos de um Latossolo Vermelho Distroférrico sob sistema de semeadura direta. Bragantia, vol. 70, n. 4, p. 908-916. http://dx.doi.org/10.1590/ S0006-87052011000400025

Dalchiavon, F.C.; Montanari, R.; Andreotti, M.; Dallacort, R. e Souza, M.F.P. (2015) - Relationship between sunflower productivity and soil's chemical properties by geo-statistical techniques. African Journal of Agricultural Research, vol. 10, n. 35, p. 3525-3532. http://dx.doi.org/10.5897/AJAR2014.9472

Dalchiavon, F.C.; Neves, G. e Haga, K.I. (2016) - Efeito de estresse salino em sementes de Phaseolus vulgaris. Revista de Ciências Agrárias, vol. 39, n. 3, p. 404-412. http://dx.doi.org/10.19084/RCA15161

Dallacort, R.; Martins. J.A.; Inoue, M.H.; Freitas. P.S.L. e Coletti, A.J. (2011) - Distribuição das chuvas no município de Tangará da Serra, médio norte do Estado de Mato Grosso, Brasil. Acta Scientiarum Agronomy, vol. 33, n. 2, p. 193-200. http://dx.doi.org/10.4025/actasciagron.v33i2.5838

Dickson, M.H. e Petzold, R. (1989) - Heat tolerance and pod set in green beans. Journal of the American Society for Horticultural Science, vol. 114, n. 5, p. 833-836.

EMBRAPA (2013) - Sistema brasileiro de classificação de solos. Empresa Brasileira de Pesquisa Agropecuária. Centro Nacional de Pesquisa de Solos. Brasília: Embrapa Produção de informação. 353 p.

Ferreira, D.F. (2011) - Sisvar: a computer statistical analysis system. Ciência e Agrotecnologia, vol. 35, n. 6, p. 1039-1042. http://dx.doi.org/10.1590/S1413-70542011000600001

Guimarães, G.M.; Stone, L.F. e Brunini, O. (2006) - Adaptação do feijoeiro comum à seca. Revista Brasileira de Engenharia Agrícola e Ambiental, vol. 10, n. 1, p. 70-75. http://dx.doi.org/10.1590/51415-43662006000100011

Melo, L.C.; Melo, P.G.S.; Faria, L.C.; Diaz, J.L.C.; Del Peloso, M.J.; Rava, C.A. e Costa, J.G.C. (2007) - Interação com ambientes e estabilidade de genótipos de feijoeiro-comum na Região Centro-Sul do Brasil. Pesquisa Agropecuária Brasileira, vol. 42, n. 5, p. 715-723. http://dx.doi.org/10.1590/S0100-204X2007000500015

Morais, L.K. de.; Carbonell, S.A. M.; Pinheiro, J.B.; Fonseca Jr, N. da S. e Brasil, E.M. (2001) - Avaliação de cultivares de feijoeiro, Phaseolus vulgaris L., sob diferentes espaçamentos. Acta Scientiarum Agronomy, vol. 23, n. 5, p. 1199-1203. http://dx.doi.org/10.4025/actasciagron.v23i0.2574

O'Toole, J.C.; Ozbun, J.L. e Wallace, D.H. (1977) - Photosynthetic response to water stress in Phaseolus vulgaris. Physiologia Plantarum, vol. 40, n. 2, p. 111-114. http://dx.doi.org/10.1111/j.1399-3054.1977.tb01505.x

Oliveira, A.D.; Fernandes, E.J. e Rodrigues, T.J.D. (2005) - Condutância estomática como indicador de estresse hídrico em feijão. Engenharia Agrícola, vol. 25, n. 1, p. 86-95. http://dx.doi.org/10.1590/\$0100-69162005000100010

Oliveira, I.B.; Mendonça, G.W.; Binotti, F.F.S.; Ascoli, A.A. e Costa, E. (2015) - Fertilizante foliar em feijoeiro de inverno e sua influência na produtividade e qualidade fisiológica das sementes. Revista de Agricultura Neotropical, vol. 2, n. 2, p. 57-67.

Pereira, H.S.; Melo, L.C.; Faria, L.C.; Del Peloso, M.J.; Costa, J.G.C.; Rava, C.A. e Wendland, A. (2009) Adaptabilidade e estabilidade de genótipos de feijoeiro-comum com grãos tipo carioca na Região Central do Brasil. Pesquisa Agropecuária Brasileira, vol. 44, n. 1, p. 29-37. http://dx.doi.org/10.1590/50100-204X2009000100005

Pimentel-Gomes, F.P. e Garcia, C. H. (2002) - Estatística aplicada a experimentos agronômicos e florestais. Piracicaba: FEALQ, 309 p.

Ramalho, M.A.P.; Silva, G.S. e Dias, L.A.S. (2009) - Genetic plant improvement and climate changes. Crop Breeding and Applied Biotechnology, vol. 9, n. 2, p. 189-195.

Santos, C.M. dos; Carvalho, M.A.C. de; Rodrigues, M.; Noujain Filho, N. e Mendes, E.D.R. (2013) Comportamento de genótipos de feijão na época "das águas" no Norte de Mato Grosso. Revista de Ciências Agro-Ambientais, vol. 11, n. 1, p. 17-26.

Santos, F.A.S. e Lima de A.R. (2015) - Características produtivas de diferentes cultivares de feijão no Município de Cáceres-MT. Centro Científico Conhecer, vol.11, n. 21, p. 408-420.

Silva, V.R.; Reichert, J.M. e Reinert, D.J. (2006) - Variação na temperatura do solo em três sistemas de manejo na cultura do feijão. Revista Brasileira de Ciências do Solo, vol. 30, n. 3, p. 391-399. http://dx.doi.org/10.1590/S010006832006000300001

Souza, D.M.G. e Lobato, E. (2004) - Cerrado: correção do solo e adubação. 2 ed. Brasília: Embrapa Cerrados. $295 \mathrm{p}$. 
Vale, M.N.; Barili, D.L.; Rozzeto, S.D.; Stinghin, C.J.; Coimbra, M.L.J.; Guidolin, F.A. e Köop, M.M. (2012) - Avaliação para tolerância ao estresse hídrico em feijão. Revista Biotemas, vol. 25, n. 3, p. 135-144. http:// dx.doi.org/10.5007/2175-7925.2012v25n3p135

Valério, C.R.; Andrade, M.J.B. e Ferreira, D.F. (1999) - Comportamento das cultivares de feijão aporé, carioca e pérola em diferentes populações de plantas e espaçamentos entre linhas. Ciência e Agrotecnologia, vol. 23, n. 3, p. 515-528. 